\title{
Tracking Police Arrests of Intimate Partner Domestic Abuse Suspects in London: a Situational Factors Analysis
}

\author{
Owain Richards ${ }^{1} \cdot$ Vincent Harinam ${ }^{2}$
}

Published online: 18 August 2020

(C) The Author(s) 2020

\section{Abstract}

Research Question What were the odds of named suspects being arrested for a reported crime of intimate partner abuse over one 12-month period in one area of London (UK), and how did those odds vary across twelve predictive situational characteristics, including the presence or absence of the suspect?

Data This study analyses 1000 intimate partner domestic abuse (DA) crimes recorded in the South West Basic Command Unit of the London Metropolitan Police Service in the 12 months between 1 February 2018 and 31 January 2019.

Methods Twelve factors present at the time of police recording an intimate partner abuse crime were analysed in an odds ratio analysis predicting whether a named suspect would be arrested for the crime. Separate analyses were conducted for cases in which the suspect was present at the time police arrived to interview the victim and in cases in which the suspect was absent. Analyses were also conducted by crime type and crime severity scores, with a descriptive analysis of reasons police gave for not making arrests. Findings Police arrested the suspect in $90 \%$ of the 287 cases in which suspects were present when police arrived, and in $47 \%$ of the 713 cases in which the suspect was absent on arrival. There was no difference in crime severity scores between cases in which arrests were made vs. not. After suspect absence, victim unwillingness to press charges was the second strongest predictor of no arrest being made, with $21 \%$ reported unwilling to cooperate when suspects were present and $29 \%$ unwilling when suspects were absent. Arrests were more likely when suspects were male than female and less likely with male victims than female victims.

Conclusions These data show that in an area housing about $12 \%$ of London's population, police make arrests in $90 \%$ of intimate partner crimes when the suspect is still present at the scene, and almost half of those in which suspects leave before police arrive. The primary predictor of non-arrest, controlling for offender absence, is victim unwillingness to support prosecution. Various policy options can be considered in light of these findings.

Vincent Harinam

vh315@cam.ac.uk

Extended author information available on the last page of the article 
Keywords Intimate partner abuse $\cdot$ Arrest $\cdot$ Tracking $\cdot$ Predictive factors

\section{Introduction}

Domestic abuse is a key strategic priority for the Metropolitan Police Service (MPS), which defines such crimes as "any incident or pattern of incidents of controlling, coercive or threatening behaviour, violence or abuse between those aged 16 or over who are or have been intimate partners or family members regardless of gender or sexuality." Intimate partners are therefore not the only category of domestic abuse, but they are a subset of major importance.

This study tracks the rate of arrests for recorded intimate partner domestic abuse cases in a police area serving $12 \%$ of London's resident population. Our aim is to identify both the situational factors associated with arrest decisions and officers' reasons for non-arrest decisions. We do this by examining police records on 1000 intimate partner domestic abuse crimes in the South West Basic Command Unit of the Metropolitan Police Service (MPS) in London between 1 February 2018 and 31 January 2019.

We present this study in the context of a growing emphasis on tracking police decision-making as one of the three pillars of the framework for evidence-based policing (Sherman 2013): targeting, testing, and tracking. The importance of tracking is that it tells police leaders what policy is actually being delivered, as distinct from being adopted. For example, a February 2019 report on police response to domestic abuse in England and Wales revealed that the arrest rate had fallen from 52 arrests per 100 offenders in 2016 to 45 per 100 in 2017 (HMICFRS 2019).

Yet the measurement of rates over time must also be tempered with possible changes in the counting rules for the denominators, as well as for the numerators. Thus, a declining arrest rate in 2016-2017 must be reconciled with a $23 \%$ increase in policerecorded domestic abuse crimes in 2018 (ONS 2018), which may in turn reflect an increasing proportion of domestic incidents being classified as crimes nationwide.

Rather than focusing on trend analysis, this study examines differences across cases within a single time and place with apparently constant definitions of what qualifies as a crime in each case under Home Office Recording Standards. This approach builds on a long tradition of analysing arrest decisions in general (Reiss 1971; Black 1980), as well as for domestic abuse in particular.

\section{Situational Factors Affecting Domestic Abuse Arrests}

Four decades ago, and well before the global (Common Law) shift towards positive arrest actions in such cases, Berk and Loseke (1980) showed that several situational variables predicted officers' decisions to arrest suspects: victim preference, the presence of both the victim and suspect at the scene, and the use of violence by male offenders. Other studies have highlighted suspect presence as a major situational factor in prompting an arrest (Berk and Loseke 1980; Sherman et al. 1992a, b; Feder 1996; Hirschel et al. 2007). Given that "suspect not present" is the predominant reason given by police officers for non-arrest, Sherman notes that, "If the suspect is not at the scene, the odds of apprehending the offender in the long run diminishes with time" (Sherman 
et al. 1992a, b p. 207). Feder (1996), investigating differences between present and absent domestic abuse offenders, found that offender presence was the most powerful predictor of an arrest outcome. Hall (2005) elaborates further upon this, finding that the seriousness of the offence most explained the decision to arrest when the offender was present, while the absence of the suspect significantly reduced the probability of arrest. Hirschel and Buzawa (2009) reported that a domestic abuse offender who leaves the scene is nearly six times less likely to be arrested than an offender who remains. There is also strong evidence pointing to the impact of victim preference on arrest (Buzawa and Austin 1993; Beale 2008).

\section{Research Question}

The central research question for this study is what were the odds of a named suspect being arrested for a reported crime of intimate partner abuse in one area of London (UK), and how did those odds vary across twelve predictive situational characteristics? We answer this general question with evidence on four specific aspects of the question:

1. What recorded information on 12 predictive situational factors is associated with the decision to arrest or not arrest in domestic abuse crimes in the MPS?

2. Does the predictive accuracy of those factors differ depending on whether the suspect is present on police arrival or not?

3. Do the results vary depending on crime harm and specific crime types?

4. What is the recorded rationale for non-arrest given a force policy of "positive action"?

This study builds on previous research (Beale 2008) on police use of arrests in another English police agency a decade earlier. We replicate and extend Beale's approach by also analysing free-text data in officer reports to describe their rationales for non-arrest decisions.

\section{Data}

This study analyses 1000 intimate partner domestic abuse crimes recorded in the South West Basic Command Unit (BCU) of the London Metropolitan Police Service between 1 February 2018 and 31 January 2019. The South West BCU is comprised of the London boroughs of Wandsworth, Richmond, Kingston and Merton, with a population of approximately one million residents. All cases were reported to involve current or former intimate partners; they include no cases of domestic abuse involving other family relationships (e.g. parent-child, sibling). The beginning and end dates were chosen to (1) allow enough time for cases to be concluded with an arrest outcome (or not) and to (2) mitigate seasonal peaks or valleys in frequency of reported domestic abuse that might result in changing arrest rates.

The chosen domestic abuse incidents were all closed cases where criminal investigations were concluded with a decision to arrest. Initially, all DA flagged crimes for the South West BCU were downloaded from the MPS information system called "CRIS" 
( $N=7584$ within the time period) and exported into Excel. The subset of intimate partner cases was identified by using a filter on Excel to isolate all victim/suspect relationship types. The number classified as "current or former partner" $=3855$. Using a formula within Excel, we selected a random sample of 1000 of the current or former partner cases.

Upon first examining the 1000 cases, they appeared to show 484 arrests and 516 non-arrests. However, a manual check of the free-text records for all non-arrest records needed to be undertaken to ensure that the "non-arrest" classification was correct. Closer examination of the free-text data revealed that 61 suspects had been arrested at the scene of the domestic abuse incident despite being marked as having not been arrested. This comprised a $6.1 \%$ error rate in the study sample, which was corrected by reclassifying the cases to be consistent with the text. In addition, suspects who were not present at the scene of crime but were later issued with an arrest warrant were placed in the "arrested" category. These changes produced a final tally of 592 domestic abuse suspects who were coded as arrested and 408 who were not.

We also measure the crime harm of each domestic abuse case. The Office for National Statistics crime severity score is used to attach a numerical weighting to each crime (ONS 2016). All recorded crimes are quality-assured by the MPS' Crime Management Unit who validates each offence classification against a set list of Home Office codes. These codes were matched against the crime severity scores to produce a harm value for all 1000 domestic abuse offences. The crime severity scores within the dataset ranged from 5 (e.g. criminal damage under five hundred pounds) to 2953 (e.g. rape of a female over 15).

Twelve independent factors were selected for analysis after considering the literature and their availability in MPS databases. There were 11 binary factors: address flagged for domestic abuse (yes/no), body-worn camera evidence (yes/no), CCTV evidence (yes/no), domestic abuse witnessed (yes/no), suspect gender (male/female), suspect present on police arrival (yes/no), suspect previous history (yes/no), use of weapons (yes/no), victim gender (male/female), victim unwilling (yes/no) and victimised in past 12 months (yes/no). The single continuous variable was the crime severity score.

\section{Methods}

To compare the relative predictive power of each of the situational factors we measured, we used odds ratios and $t$ tests. In general, these statistics provide a clear interpretation of the data. The association between the eleven binary factors and the decision to arrest was calculated using odds ratios. Odds ratio was produced across all 1000 cases and again for the subset of cases in which the suspect was present at the scene of the crime when police arrived.

The odds of arrest were also calculated for three specific crime types: actual bodily harm, common assault and harassment. These crime types were chosen based on their high prevalence in the dataset. Results are presented in a forest plot and rank ordered by their odds ratio value. An independent sample $t$ test was conducted to investigate whether the crime severity scores differed among arrested and non-arrested suspects.

Finally, a manual review of the free-text data was undertaken. Each of the non-arrest crimes $(n=408)$ was manually checked by reading the free-text narrative to search for the officer's recorded rationale for non-arrest. The recorded reasons were then 
categorised and rank ordered in descending order. Analyses and visualisations were produced using Microsoft Excel and R.

\section{Findings}

Figure 1 presents the results of the odds ratios for all 1000 cases. Eight of the 11 factors have an odds ratio greater than 1 , which means that their presence increased the odds of arrest. Notably, the factor which most increased the odds of arrest is the suspect's presence upon the officer's arrival at the scene. Indeed, the odds of arrest is 9.67 times greater when suspects are present upon police arrival relative than when they are not. The presence of a police body-worn camera and the use of a weapon by the suspect ranked second and third, respectively, to increase the odds of arrest 6.42 and 5.01 times. If the suspect is male, the odds of arrest are 2.26 times higher than if the suspect were female.

Nevertheless, two factors decreased the odds of arrest to a statistically significant degree: a victim who is unwilling to support an arrest and a victim who is male. Indeed, the odds of arrest are $46 \%$ lower if the victim is male, and $78 \%$ lower if the victim (of either gender) is unwilling to support arrest at the scene, respectively. This suggests both the importance of victim gender and victim willingness, with officers far more likely to arrest when the victim is female and willing to support arrest.

To test whether or not the crime severity scores differ between those arrested and not arrested, an independent sample $t$ test was conducted. The result shows that crime severity had virtually no effect on arrest outcomes. The mean crime severity score of those arrested was 182.02 days of average imprisonment for those convicted of such offences, and of those not arrested it was 180.62.

\section{Suspect Presence or Absence in the Decision to Arrest}

How might the prevalence of these situational factors change when controlling for suspect presence? Of the 1000 domestic abuse crimes, there were 287 cases in which the suspects were present on police arrival, of which 257 (89.5\%) were arrested and 30 $(10.5 \%)$ were not arrested. In comparison, in 713 cases, suspects were absent on police arrival, of whom $335(47 \%)$ were arrested and $378(53 \%)$ were not arrested. Figures 2

\begin{tabular}{|c|c|c|c|c|}
\hline Factor & Odds & OR Sig. & \multicolumn{2}{|c|}{ Odds Ratio $(95 \% \mathrm{CI})$} \\
\hline ( $n=287$ ) Suspect present on arrival & 9.67 & $<0.001$ & & \\
\hline ( $n=574)$ Body worn camera evidence & 6.42 & $<0.001$ & & \\
\hline$(n=32)$ Weapon used & 5.01 & $<0.001$ & & \\
\hline ( $n=553$ ) Previous suspect history & 2.75 & $<0.001$ & & \\
\hline$(n=742)$ Male suspect & 2.26 & $<0.001$ & & \\
\hline$(n=322)$ Victimised in past 12 months & 1.4 & 0.02 & & \\
\hline ( $(n=63)$ Address flagged & 1.31 & 0.3561 & & \\
\hline ( $n=302)$ DA Witnessed & 1.09 & 0.58 & & \\
\hline ( $n=29)$ CCTV evidence & 0.82 & 0.7 & ? & \\
\hline$(n=205)$ Male victim & 0.54 & $<0.001$ & 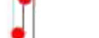 & \\
\hline ( $n=269$ ) Victim unwilling & 0.22 & $<0.001$ & & \\
\hline
\end{tabular}

Fig. 1 Odds of arrest for all suspects (1000 cases) 
and 3 display the odds of arrest according to the other situational factors when controlling the strongest predictor: suspect presence and absence at the scene.

These findings show that only three situational factors have a statistically significant effect on the odds of arrest when the suspect is present at the scene: a male suspect, a male victim and a victim who is unwilling to cooperate with a prosecution. When the suspect was not present.

A comparison of Figs. 2 and 3 shows that there is little variance in arrest decisions when suspects are present but substantial variance when they are not. Only three predictors are greater than chance with suspects present: a male suspect, a male victim or a victim unwilling to prosecute. But when suspects are absent, seven predictors fully exceed chance in whether an arrest will occur: weapon used by suspect, body-worn camera worn by police, previous suspect history, male suspect, victimisation of the victim in the past 12 months, male victim and victim's unwillingness to support arrest. Notably, male suspect is the only situational factor which increases the odds of arrest when the suspect is present upon arrival. While this variable also increases the odds of arrest when the suspect is absent, it is outranked by weapon used, body-worn camera used and previous suspect history.

In general, we observe a qualitative difference in the factors which influence the decision to arrest between the two groups. While the gender of the suspect and victim plays an important role in an officer's decision to arrest when the suspect is present, situational factors relating to evidence at scene carry greater weight when the suspect is absent. Nevertheless, victim's unwilling to support arrest decreases the odds of arrest regardless of whether the suspect is present at the scene of the domestic abuse.

\section{Victim Willingness to Support Charges}

The substantial correlation of victim unwillingness to support charges with a no-arrest outcome can be understood more fully in light of the reasons for non-arrest recorded by the responding officers. The following statements are illustrative (Richards 2019, p. 94):

- The complainant did not want the suspect for this matter to be arrested; only spoken to I have eliminated the suspect.

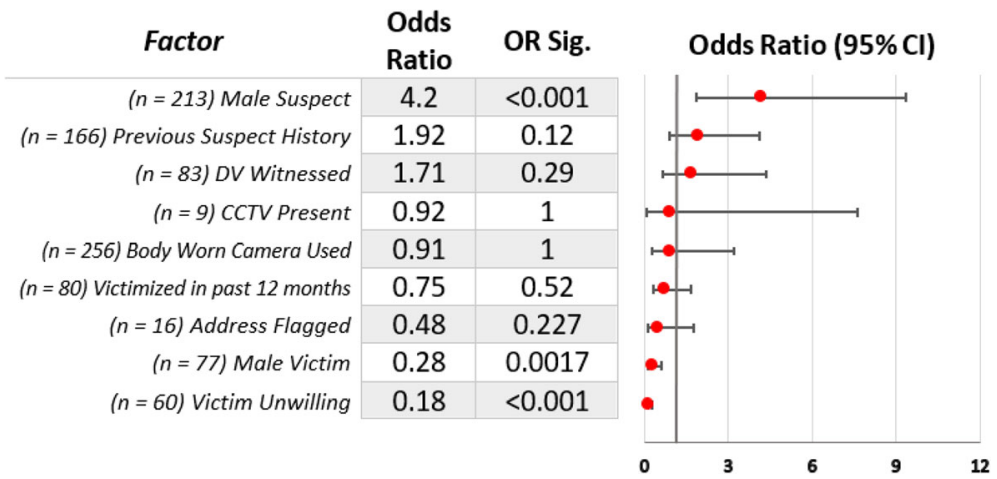

Fig. 2 Odds of arrest for present suspects $(N=287)$ 


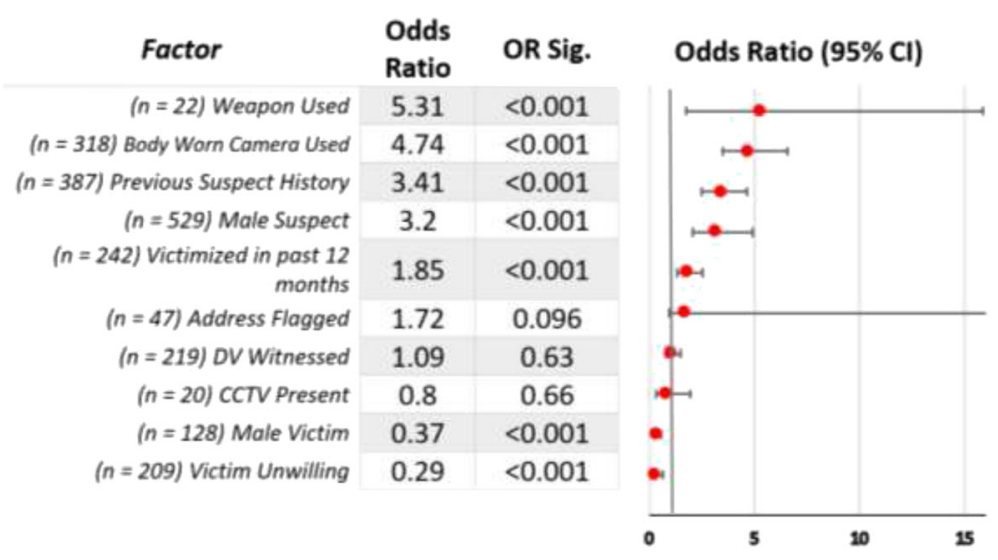

Fig. 3 Odds of arrest for absent suspects $(N=713)$

- She does not wish to make any allegation of harassment against the suspect; she is concerned about his welfare and his mental health.

- She does not necessarily want to proceed with prosecution.

- He does not wish to proceed with the allegation against $<<$ nameremoved $>>$ and is adamant that he does not support any further action against him.

- He doesn't wish to provide any evidence of communication and doesn't want to pursue any prosecution against the female concerned at this time. He does not wish for me to speak to her.

- Adamant she doesn't want police to pursue this case further, victim has refused from outset to provide an evidential account in relation to initial allegation.

- He doesn't want $<<$ nameremoved $>>$ to be arrested, and only wants her to be given words of advice. Victim is unwilling to co-operate

- Neither party wanting to give a statement to police neither party wanting the other party to be arrested.

- __ _ does not wish to pursue criminal allegation and simply wants him to attend hospital for mental health treatment/assessment.

- Does not wish to pursue a prosecution in relation to this and does not wish for me to contact the suspect in any way.

\section{Conclusions}

This research examines some of the situational factors which predict arrests in intimate partner cases of domestic abuse crimes. It shows, for perhaps the first time, precisely how much police contact with victims occurs after suspects have left and how powerful a predictor their departure is for a no-arrest outcome: arrest is nearly ten times more likely if the suspect is present than absent. The study also shows, however, that the noarrest outcome is exactly what victims preferred in almost one-third (29\%) of the 713 cases in which offenders had left or 217 of all suspect-absent cases.

Nevertheless, there is a mixture of other situational factors that increase the odds of arrest, especially when the suspect has departed before police arrive. These factors include body-worn camera evidence, the use of weapons by suspects, previous suspect 
history, male suspects and previous victimisations within the past 12 months. Such information provides officers with an evidence-based foundation from which the decision to arrest can be made.

The increased odds of arrest when body-worn camera evidence is available invite further attention. While we cannot say that officers are more likely to pursue absent suspects if they obtain video evidence of victim injuries, for example, it would be important to conduct further research on such possibilities.

Two other predictors also invite further analysis because they decrease the odds of arrest: a victim's unwillingness to support arrest and a victim who is male. At face value, the notion that male victimhood decreases the odds of arrest raises questions about officer discretion. This particular result may be due to officers' bias in favour of female victims. That is, officers may either perceive female victims as more vulnerable relative to male victims or simply assume that it is mainly male suspects who commit domestic abuse based on prior experiences in the field. An officer's decision not to arrest when the male is a victim may reflect a heuristic born of their experiences in dealing with domestic abuse.

It is not surprising, however, that victims' unwillingness to support arrest decreases the odds of arrest by $78 \%$. Indeed, the domestic abuse literature indicates that victim preference in supporting arrest and/or investigation is consistently important in police decision-making (Berk and Loseke 1980; Sherman et al. 1992a, b, pp. 31-32; Buzawa and Austin 1993). Interestingly, this is also consistent with findings derived from an MPS staff survey (2018) ( $n=888$ frontline officers), wherein the victim's unwillingness to support an arrest or investigation reduced the likelihood of arrest. This pattern, however, runs contrary to the explicit policy guidelines of the MPS, which stipulates that "a victim's decision not to engage in the criminal justice process is not a reason not to arrest."

Nevertheless, MPS officers must choose between overriding the victim's wishes in compliance with a policy of positive action advocating arrest or disobeying organisational policy in order to accede to the victim's wishes and not arrest. This binary choice raises the question of whether other victim protection or risk management options should be developed as an alternative to arrest.

In this context, it seems important that this study is the first to focus on the association between arrest outcomes and specific situational factors when suspects are absent. When the suspect is present, only two predictors of arrest were statistically significant: victim unwillingness to cooperate and suspect gender. When the suspect is absent, many other predictors show strong correlations: the use of weapons by suspects, body-worn camera evidence, suspect previous criminal history, repeat victimisation of the victim and suspect gender all increase the odds of arrest.

The separate findings for present and absent offenders help us to see clear differences in the factors associated with arrest. These results suggest that while officers may rely on the heuristic of gender to make their arrest decision when the suspect is present, they may attempt to examine further "guideposts" to priorities by gathering circumstantial evidence at the scene when the suspect is absent. While the extant literature touches on this mechanism, it has not previously been explored in such detail.

When controlling for three crime types, actual bodily harm, common assault and harassment, the results (Richards 2019) suggest little difference. This finding is corroborated by the fact that crime severity was no greater or smaller for the cases leading to arrest than for those that did not. However, it is difficult to draw a firm conclusion given the small number of cases. 
Finally, a review of the officers' recorded rationale for non-arrest shows that victim unwillingness to support an arrest is the modal reason, with $44 \%$ (180) of cases possessing this rationale. The remaining $56 \%$ of cases had a mixture of rationales including suspects agreeing to a voluntary interview, legal reasons and suspects issued with a harassment warning notice. This finding is perhaps the most challenging to reconcile given the complexities of domestic abuse and MPS policy that a victim's lack of engagement is not a reason to not arrest a suspect.

\section{Policy Implications}

Whatever the deterrent effect of this strategy on domestic abuse perpetrators, police officers may legally use their discretion to decide whether an arrest is in the public interest in each case. Yet how those decisions are tracked should depend on the additional public interest in police pursuing an absent suspect versus responding to other emergencies in which suspects are still present. The fact that in the majority (71\%) of this sample the suspect was already gone when police arrived could prompt some rethinking of how best to measure positive action.

There are several possible explanations for why absent suspects have a lower arrest rate than those present. These include the ease of arrest execution for a present suspect, absent suspects being more difficult to track down after the fact and workload pressures that accumulate down the line for responding officers. The predictive factors identified in this study (e.g. the use of weapons, body-worn camera evidence, suspect previous history, repeat) suggest that officers are already imposing a public interest test on whether to pursue absent suspects.

Given the proportion of suspects not arrested due to victim preference, it may also be time to consider an alternative to arrest which also represents a positive action to safeguard the victim and reduce offending. If the arrest rate is nudged upwards by addressing the error rate and better use of information readily available to officers, there is an opportunity for senior officers to channel the drive and energy currently spent on the domestic abuse arrest rate toward exploring other ways to reduce victim harm.

To support officers in making arrest decisions, the information needed to make the best decisions must be immediately available to them. First, if a heightened risk of domestic abuse is known at an address, ways could be found to relay this information to officers before arriving at the scene. Second, police dispatch systems could do more to ensure that flagging information is communicated immediately to the officer responding to a domestic abuse call. The same should be done for suspect's previous criminal history, whereby a PNC check could be done before the officer arrives at the scene.

In short, the ability to provide officers with better information and intelligence about the background of a domestic abuse might well improve the officer's decision-making and compliance with the current positive arrest policy. If the addresses are accurately flagged to indicate a harmful domestic abuser, the information could be used to provide a more focused means of targeting resources. Nevertheless, the message for policy makers and frontline officers is clear: suspect presence and victim preference make a difference in arrest decision-making. We can, however, improve arrest intervention and compliance by ensuring that officers are fully supported with the best evidence for the best decisions for all victims. 
Acknowledgements The authors wish to thank the Metropolitan Police Service for sponsoring the first author's enrolment in the Cambridge University Police Executive Programme's Master of Studies course in applied criminology and police management and for supplying the data employed in this research. The first author offers special thanks to his thesis supervisor, Sir Denis O’Connor CBE QPM.

\section{Compliance with Ethical Standards}

Conflict of Interest From 1 November 2018 through the acceptance of this article in July 2020, the first author was the Detective Superintendent in charge of public protection in the study area, including the last 3 months of the study period in the study area, the South West BCU. He did not have line management responsibility for the decisions tracked in this study, but did report to the Chief Superintendent who held that responsibility.

Open Access This article is licensed under a Creative Commons Attribution 4.0 International License, which permits use, sharing, adaptation, distribution and reproduction in any medium or format, as long as you give appropriate credit to the original author(s) and the source, provide a link to the Creative Commons licence, and indicate if changes were made. The images or other third party material in this article are included in the article's Creative Commons licence, unless indicated otherwise in a credit line to the material. If material is not included in the article's Creative Commons licence and your intended use is not permitted by statutory regulation or exceeds the permitted use, you will need to obtain permission directly from the copyright holder. To view a copy of this licence, visit http://creativecommons.org/licenses/by/4.0/.

\section{References}

Beale, M. (2008). Understanding arrests for domestic violence in Staffordshire - an exploratory analysis (Unpublished in MSt. thesis, University of Cambridge).

Berk, S.F. and Loseke, D.R. (1980) Handling family violence: situational determinants of police arrest in domestic disturbances. Law and Society Review, pp 317-346.

Black, Donald. 1980. The Manners and Customs of the Police. New York: Academic Press.

Buzawa, E. S., \& Austin, T. (1993). Determining police response to domestic violence victims: the role of victim preference. The American Behavioral Scientist, 36(5), 610-623.

Feder, L. (1996). Police handling of domestic calls: the importance of offender's presence in the arrest decision. Journal of Criminal Justice, 24(6), 481-490.

Hall, D. L. (2005). Domestic violence arrest decision-making: the role of suspect availability in the arrest decision. Criminal Justice and Behavior, 32(4), 390-411.

Her Majesty's Inspectorate of Constabulary and Fire \& Rescue Services, (2019). The police response to domestic abuse. An update report. Retrieved 19th April 2019 from https://www.justiceinspectorates.gov. $\mathrm{uk} / \mathrm{hmicfrs} /$ publications/the-police-response-to-domestic-abuse-an-update-report/.

Hirschel, D. and Buzawa, E. (2009) An examination of the factors that impact the likelihood of arrest in intimate partner violence cases. In Annual Meeting of the Justice Research Statistical Association, St. Louis, MO.

Hirschel, D., Buzawa, E., Pattavina, A., \& Faggiani, D. (2007). Domestic violence and mandatory arrest laws: to what extent do they influence police arrest decisions. Journal of Criminal Law \& Criminology, 98, 255.

Office for National Statistics, $30^{\text {th }}$ November 2016. Research outputs: developing a Crime Severity Score for England and Wales using data on crimes recorded by the police. Retrieved $1^{\text {st }}$ May 2019 from https:/www.ons.gov.uk/peoplepopulationandcommunity/crimeandjustice/articles/researchoutputs developingacrimeseverityscoreforenglandandwalesusingdataoncrimesrecordedbythepolice/2016-11-29.

Office for National Statistics, 22 ${ }^{\text {nd }}$ November 2018. Domestic abuse in England and Wales: year ending March 2018. Retrieved 22nd April 2019 from https://www.ons.gov. $\mathrm{uk} /$ peoplepopulationandcommunity/crimeandjustice/articles/domesticabusefindingsfromthecrime surveyforenglandandwales/yearendingmarch2018.

Reiss, A.J. (1971). The Police and the Public. New Haven: Yale University. 
Richards, O. (2019). An exploratory study of police arrest decisions with intimate partner domestic abuse suspects in the Metropolitan Police Service. Unpublished M.St. thesis, Police Executive Programme, Institute of Criminology, University of Cambridge.

Sherman, L. W. (2013). The rise of evidence-based policing: targeting, testing, and tracking, Crime and justice: a review of research, Vol. 42 (pp. 377-447). Chicago: University of Chicago Press.

Sherman, L.W., Schmidt, J.D. and Rogan, D.P., (1992a) Policing domestic violence: experiments and dilemmas. Free Press.

Sherman, L. W., Schmidt, J. D., Rogan, D. P., \& Smith, D. A. (1992b). The variable effects of arrest on criminal careers: the Milwaukee domestic violence experiment. Journal of Criminal Law \& Criminology, $83,137$.

Publisher's Note Springer Nature remains neutral with regard to jurisdictional claims in published maps and institutional affiliations.

Owain Richards M.St. (Cantab) is a Detective Superintendent in the Metropolitan Police Service with responsibility for public protection in the boroughs of Kingston, Richmond, Merton and Wandsworth, including the area in which this study was conducted. He joined the Metropolitan Police Service in March 2015 having started his policing career 20 years earlier at Dyfed-Powys Police, Wales.

Vincent Harinam M.Sc. (Toronto) is a $\mathrm{PhD}$ candidate at the Institute of Criminology, University of Cambridge, and a project manager at the Cambridge Centre for Evidence-Based Policing.

\section{Affiliations}

\section{Owain Richards ${ }^{1} \cdot$ Vincent Harinam ${ }^{2}$}

1 Metropolitan Police Service and Institute of Criminology, University of Cambridge, Cambridge, UK

2 Institute of Criminology, University of Cambridge, Cambridge, UK 